\title{
Comparison of Temporal Bone Parameters before Cochlear Implantation in Patients with and without Facial Nerve Stimulation
}

\author{
Venkatkrish Manohar Kasetty ${ }^{1}$, Zachary Zimmerman $^{2},{\text { Sarah } \mathrm{King}^{2} \text {, and Mohammad Seyyedi }}^{2}$ \\ ${ }^{1}$ Medical College of Georgia, Augusta University, Augusta, GA, USA \\ ${ }^{2}$ Department of Otolaryngology-Head and Neck Surgery, Medical College of Georgia, Augusta University, Augusta, GA, USA
}

Received April 27, 2019

Revised June 16, 2019

Accepted July 26, 2019

\section{Address for correspondence \\ Mohammad Seyyedi, MD \\ Department of Otolaryngology- \\ Head and Neck Surgery, \\ Medical College of Georgia, \\ Augusta University, 1120 15th Street, \\ BP 4109, Augusta, GA 30912, USA \\ Tel $+1-706-721-6100$ \\ Fax +1-706-721-0112 \\ E-mail MSEYYEDI@augusta.edu}

\begin{abstract}
Background and Objectives: Facial nerve stimulation (FNS) is a complication of cochlear implantation $(\mathrm{Cl})$. This study compared the thickness and density of the bone separating the upper basal turn of the cochlea (UBTC) and the labyrinthine segment of the facial nerve (LSFN) on preoperative computed tomography (CT) in patients with and without FNS after Cl. Subjects and Methods: Adult patients who underwent Cl from January 2011 to February 2017 with preoperative CT at a tertiary referral hospital were considered for this retrospective casecontrol study. Patients were divided into two groups: with FNS $(n=4)$ and without FNS $(n=53)$. The density and thickness of the bone between the LSFN and UBTC were measured on preoperative CT. Charts were reviewed for other parameters. Results: A statistically significant difference was seen in the thickness $(p=0.007)$ but not in the density $(p=0.125)$ of the bone between the UBTC and LSFN. Four patients had FNS at the mid-range electrode arrays, and one of them additionally had FNS at the basal arrays. Conclusions: Decreased thickness of the bone between the UBTC and LSFN can explain postoperative FNS, confirming the histologic and radiologic findings in previous studies, which indicated that the thickness of the temporal bone between the LSFN and UBTC is less in patients who experience FNS. While the density in this region was also less, it was not statistically significant.
\end{abstract}

J Audiol Otol 2019;23(4):193-196

KEY WORDS: Facial nerve · Electrical stimulation · Cochlear implants . Computed tomography.

\section{Introduction}

Cochlear implantation (CI) is a common procedure used to restore hearing when hearing aids are not sufficient. CI is a safe procedure with low complication rates. The complications of CI include facial nerve stimulation (FNS), vertigo, infection, meningitis, device extrusion, and device failure [1]. Stimulation of the facial nerve occurs in $1-15 \%$ of all cochlear implant recipients and can result in facial muscle twitch or spasm. This can be unnoticable to patients or can cause severe discomfort, which may stop the patients from using the

This is an Open Access article distributed under the terms of the Creative Commons Attribution Non-Commercial License (https://creativecommons.org/licenses/by-nc/4.0/) which permits unrestricted non-commercial use, distribution, and reproduction in any medium, provided the original work is properly cited. implants [2]. A previous study suggested that problems may arise in the bone separating the upper basal turn of the cochlea (UBTC) and the labyrinthine segment of the facial nerve (LSFN) [3].

UBTC is the part of the cochlea closest to the facial nerve and is the location of mid-array electrodes. A shunt of current from the electrode to the facial nerve could explain FNS after CI [4]. FNS is more prevalent in certain pathologies, such as otosclerosis [5].

Imaging procedures, such as computed tomography (CT) and/or magnetic resonance imaging (MRI), are routinely performed before implantation. They show the temporal bone anatomy, which can help the surgeon visualize any cochlear malformations and determine the candidacy for implantation, implant type, and surgical approach [6]. After CI, audiolo- 
gists work closely with the patient to adjust the implant's parameters for optimal functionality and minimum adverse effects, such as FNS. Methods to reduce FNS include changing the current level and stimulation mode or deactivating the problematic electrodes. In severe cases, removal and re-implantation may be required [2]. Preoperative imaging may be useful in predicting FNS, limiting adverse effects, and avoiding excessive subsequent procedures, especially in cases of higher risks for FNS. In this study, we evaluated the factors (thickness and density of the bone between the UBTC and LSFN) that may affect FNS.

\section{Subjects and Methods}

A retrospective case control study was performed on adult patients who underwent CI from January 2011 to February 2017, with preoperative CT and follow-up at our institution. Approval was obtained for this study from the Augusta University Institutional Review Board Office (No. 1007721). The exclusion criteria were otic capsule fracture, congenital cochlear malformation, and low-resolution CT scans. The density and thickness of the temporal bone between the LSFN and UBTC were measured on the side of CI on high-resolution axial CT scans using the IntelliSpace PACS (Philips, Andover, MA, USA) application (Fig. 1). The density was measured in Hounsfield units (HU), and the thickness was measured in millimeters ( $\mathrm{mm})$. The Statistical Package for the Social Sciences software (SPSS Statistics for MAC version 25.0; IBM Corp., Armonk, NY, USA; 2017) was used for the statistical analysis. The Mann-Whitney $U$ test was used to compare the density and thickness of the temporal bone between the LSFN and UBTC in patients with FNS to those without FNS. $p$ values $<0.05$ were considered significant.

\section{Results}

Fifty-seven patients, including 32 men and 25 women, were eligible for the study. The incidence of FNS in this study was $7 \%(4 / 57)$. The mean ages at CI of patients with and without FNS were 62.75 and 64.09 years, respectively. The mean thicknesses of the temporal bone between the LSFN and UBTC in patients with and without FNS were $0.53 \pm 0.35$ and $0.95 \pm 0.22 \mathrm{~mm}$, respectively. The mean densities of the temporal bone between the LSFN and UBTC in patients with
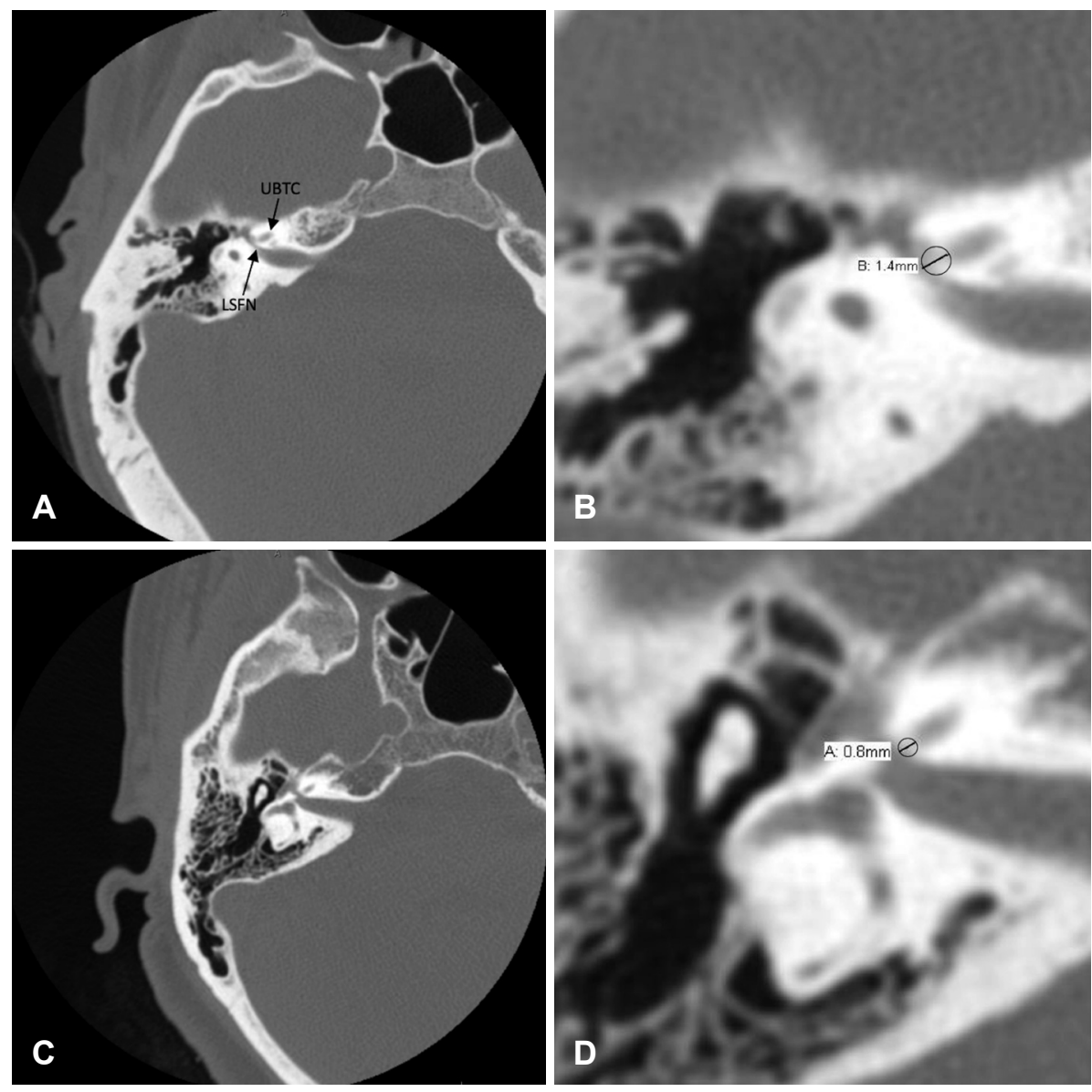

Fig. 1. Preoperative computed tomography measurements of the otic capsule. (A) A right-sided preoperative computed tomography (CT) scan of a patient who did not experience facial nerve stimulation (FNS). (B) A magnification of Fig. $1 \mathrm{~A}$ with the region of interest circled; the density and thickness of the circled region of interest were measured using the Philips Intellispace PACS (Philips, Andover, MA, USA) application. Similarly, (C, D) Right-sided preoperative CT scans of a patient who experienced FNS, with the corresponding region of interest circled; the density and thickness of this region were obtained. UBTC: upper basal turn of the cochlea, LSFN: labyrinthine segment of the facial nerve. 
and without FNS were $821 \pm 607$ and $1282 \pm 296 \mathrm{HU}$, respectively. A statistically significant difference was seen in the thickness ( $p=0.007)$ but not in the density $(p=0.125)$ of the bone between the UBTC and LSFN (Fig. 2 and 3).

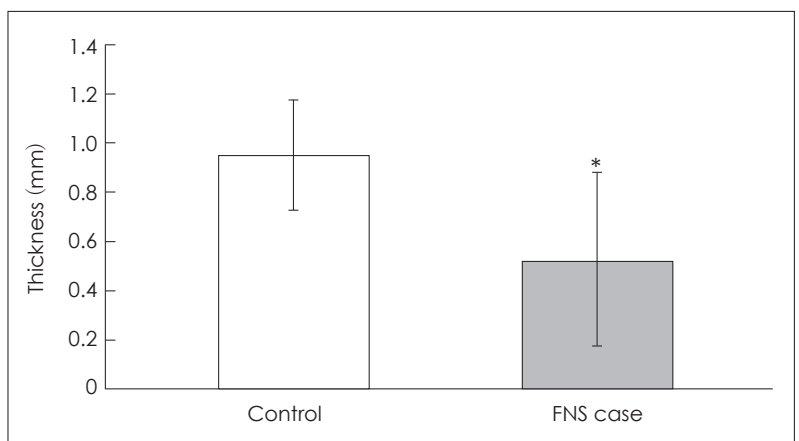

Fig. 2. The mean thicknesses of the bone between the upper basal turn of the cochlea and the labyrinthine segment of the facial nerve in patients with and without facial nerve stimulation (FNS) were $0.53 \pm 0.35$ and $0.95 \pm 0.22 \mathrm{~mm}$, respectively. A statistically significant difference was seen in the bone thickness $(p=0.007)$. ${ }^{*} p<0.05$.

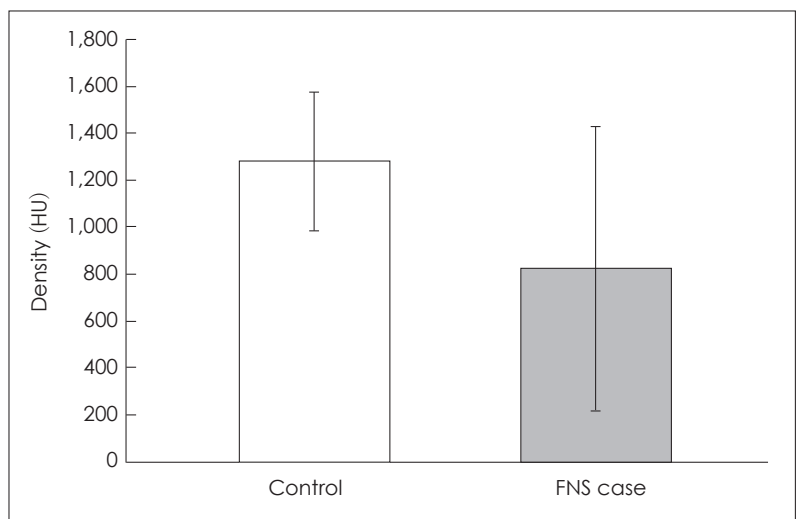

Fig. 3. The mean densities of the bone between the upper basal turn of the cochlea and the labyrinthine segment of the facial nerve in patients with and without facial nerve stimulation (FNS) were $821 \pm 607$ and $1282 \pm 296 \mathrm{HU}$, respectively. A statistically significant difference was not seen in the bone thickness $(p=0.125)$. HU: Hounsfield units.
Four patients experienced FNS at the mid-range electrode arrays associated with UBTC (Table 1). Among them, one patient also experienced FNS at the basal electrode arrays, although the implant was fully inserted. In only one patient who experienced FNS, the implant was not fully inserted.

\section{Discussion}

In a previous study with a large sample size of 600 individuals, the incidence of FNS after CI was $6.5 \%$, while in our study, it was 7\% [7]. In other studies, the incidence of FNS ranged from $1 \%$ to $15 \%$ [2]. Similar to other studies, we found that FNS usually occurs at the mid-electrode arrays, which is consistent with the electrode arrays located at the UBTC [7]. It has been hypothesized that FNS occurs because of a shunt of current from the electrode to the facial nerve at the UBTC, which is the region of the shortest distance from the electrode to the facial nerve $[3,4]$.

Many studies aimed to determine the risk factors for FNS, such as a history of irradiation, cochlear-facial dehiscence, otosclerosis, probable decrease in bone segmentation, and short distance between the facial nerve and electrode at the UBTC. Hatch, et al. [8] found that patients with FNS had a thinner bone between the electrode and facial nerve at the UBTC. In their study, the average thickness of the bone between the UBTC and LSFN was $0.3 \pm 0.3 \mathrm{~mm}$, which was not significantly different from our FNS group in a t-test ( $p=$ 0.350 ), although our non-FNS group showed a significantly larger distance between the LSFN and UBTC $(0.6 \pm 0.3 \mathrm{~mm})$ $(p<0.001)$. In our study, patients with FNS showed a lower density of the bone between the UBTC and LSFN but without statistical significance. It is possible that in high-powered studies with more patients in the FNS group, lower density becomes a risk factor for FNS. In addition, no patient in this study had otosclerosis. In a previous study on otosclerotic tem-

Table 1. Demographics and facial nerve stimulation (FNS) data

\begin{tabular}{|c|c|c|c|c|c|c|c|}
\hline Case & $\begin{array}{l}\text { Age } \\
\text { (years) }\end{array}$ & Gender & Etiology & Device & $\begin{array}{l}\text { Onset of FNS } \\
\text { after initial } \\
\mathrm{Cl} \text { activation }\end{array}$ & $\begin{array}{l}\text { Responsible } \\
\text { electrodes }\end{array}$ & Solution \\
\hline 1 & 66 & $M$ & Acquired bilateral SNHL & Med-El pulsar & 1 year & 12 & Deactivated \\
\hline 2 & 74 & $\mathrm{~F}$ & SNHL & $\begin{array}{l}\text { Med-El } \\
\text { sonata flex }\end{array}$ & 3 months & $5,6,7$ & $\begin{array}{l}\text { Current decreased in } 2 \text { electrodes. } \\
\text { Deactivated } 1 \text { electrode. }\end{array}$ \\
\hline 3 & 57 & $M$ & SNHL after meningitis & $\begin{array}{l}\text { Cochlear } \\
\text { nucleus }\end{array}$ & 2 months & $1-6$ & $\begin{array}{l}\text { Pulse width widened but FNS still } \\
\text { present. } \\
\text { Patient lost to follow-up. }\end{array}$ \\
\hline 4 & 54 & $\mathrm{~F}$ & $\begin{array}{l}\text { SNHL w/post-op meningitis. } \\
\text { History of CP angle } \\
\text { meningioma resection }\end{array}$ & Med-El pulsar & 2 years & 12 & Deactivated \\
\hline
\end{tabular}


poral bones undergoing CI, only patients with involvement of the bone between the UBTC and LSFN experienced FNS. In those cases, spongiosis reduced the density of the bone between the UBTC and LSFN [3].

As preoperative $\mathrm{CT}$ is routinely performed before $\mathrm{CI}$, it would be beneficial for surgeons if the thickness and density of the temporal bone between the UBTC and LSFN could help predict FNS in order to prevent or minimize it. Hatch, et al. [8] predicted the occurrence of FNS only in $23 \%$ of the cases. To reach this goal, we may need high-powered studies, as mentioned previously. Knowing the likelihood of FNS before CI by studying the preoperative CT scan images may help better plan the implantation.

A limitation of the study is that preoperative CT was used to obtain the measurements in three of the four cases, while postoperative CT would be better than preoperative CT to determine FNS. Postoperative CT can demonstrate the effect of the trauma caused by insertion of the implant in the temporal bone, and insertional trauma may play a role in FNS. People with thinner bones between the electrode and facial nerve may be more prone to insertional trauma, especially as the studied region of interest is located at the curve of cochlea where the electrode needs to change the trajectory to remain inside the cochlea. Therefore, the tip of the electrode may hit the cochlear outer wall and fracture the thin bone between the electrode and the LSFN at UBTC.

The sample size of 57 subjects is another limitation of this study, as it might be deemed underpowered. The thickness of the temporal bone was a statistically significant factor determining the likelihood of FNS after CI. Patients with denser temporal bone segments were less likely to experience FNS but without statistical significance. In a high-powered study, this factor could be statistically significant. Thus, the surgeon could have another objective measure of the risk of FNS after CI.

In conclusion, postoperative FNS is a relatively common complication that can occur after CI. Our study showed that patients with FNS had lower thickness of the bone between the LSFN and UBTC on CT. The density of this region was also lower in patients with FNS, although not statistically significant. These findings warrant future studies to better predict FNS preoperatively.

\section{Conflicts of interest}

The authors have no financial conflicts of interest.

\section{Author Contributions}

Conceptualization: Mohammad Seyyedi. Data curation: Venkatkrish Manohar Kasetty and Sarah King. Formal analysis: Venkatkrish Manohar Kasetty and Mohammad Seyyedi. Investigation: Venkatkrish Manohar Kasetty, Zachary Zimmerman, Sarah King, and Mohammad Seyyedi. Methodology: Mohammad Seyyedi. Project administration: Mohammad Seyyedi. Resources: Mohammad Seyyedi and Sarah King. Software: Mohammad Seyyedi. Supervision: Mohammad Seyyedi. Validation: Mohammad Seyyedi and Zachary Zimmerman. Writingoriginal draft: Venkatkrish Manohar Kasetty, Zachary Zimmerman, and Mohammad Seyyedi. Writing — review \& editing: All authors.

\section{ORCID iDs}

Venkatkrish Manohar Kasetty https://orcid.org/0000-0002-6473-3495

Zachary Zimmerman https://orcid.org/0000-0001-7948-5503

Sarah King

Mohammad Seyyedi https://orcid.org/0000-0002-3120-8459

\section{REFERENCES}

1) Farinetti A, Ben Gharbia D, Mancini J, Roman S, Nicollas R, Triglia JM. Cochlear implant complications in 403 patients: comparative study of adults and children and review of the literature. Eur Ann Otorhinolaryngol Head Neck Dis 2014;131:177-82.

2) Berrettini S, Vito DA, Bruschini L, Passetti S, Forli F. Facial nerve stimulation after cochlear implantation: our experience. Acta Otorhinolaryngologica Italica 2011;31:11-6.

3) Seyyedi M, Herrmann BS, Eddington DK, Nadol JB Jr. The pathologic basis of facial nerve stimulation in otosclerosis and multichannel cochlear implantation. Otol Neurotol 2013;34:1603-9.

4) Bigelow DC, Kay DJ, Rafter KO, Montes M, Knox GW, Yousem DM. Facial nerve stimulation from cochlear implants. Am J Otol 1998;19:163-9.

5) Espahbodi M, Sweeney AD, Lennon KJ, Wanna GB. Facial nerve stimulation associated with cochlear implant use following temporal bone fractures. Am J Otolaryngol 2015;36:578-82.

6) Kenway B, Vlastarakos PV, Kasbekar AV, Axon PR, Donnelly N. Are routine preoperative CT scans necessary in adult cochlear implantation? Implications for the allocation of resources in cochlear implant programs. Ear Nose Throat J 2016;95:318-22.

7) Smullen JL, Polak M, Hodges AV, Payne SB, King JE 3rd, Telischi FF, et al. Facial nerve stimulation after cochlear implantation. Laryngoscope 2005;115:977-82.

8) Hatch JL, Rizk HG, Moore MW, Camposeo EE, Nguyen SA, Lambert PR, et al. Can preoperative CT scans be used to predict facial nerve stimulation following CI? Otol Neurotol 2017;38:1112-7. 